\title{
Effect of Blended Fuels on Specific Fuel Consumption at Varying Engine Loads Using CVCRM Engine Test Rig
}

\author{
D.R. Prajapati ${ }^{a} *$, Gurpreet Singh ${ }^{b}$ \\ ${ }^{a}$ Department of Mechanical Engineering, PEC University of Technology (formerly Punjab Engineering College), \\ Chandigarh-160012, India \\ ${ }^{b}$ Department of Mechanical Engineering, Lovely Professional University, Phagwara (Pb)-144402, India
}

\begin{abstract}
Vegetable oils are liquid fuels from renewable sources; they do not over-burden the environment with emissions. Vegetable oils have potential for making marginal land productive by their property of nitrogen fixation in the soil. Their production requires lesser energy input in production. They have higher energy content than other energy crops like alcohol. Vegetable oils can be successfully used in CI engine, through engine modifications and fuel modifications because vegetable oil in its raw form cannot be used in engines. Specific fuel consumption (SFC) have been computed for various blends of soyabean and mustered oils with petrol at different engine loads in computerized variable compression ratio multi-fuel (CVCRM) engine test rig. It is concluded that out of the two mustard oil blends, 20-PRM shows the lowest specific fuel consumption at the engine loads of $2.5 \mathrm{Kg}$ and $5.0 \mathrm{Kg}$, where as 15 -PRM shows the lowest specific fuel consumption (SCF) at the engine loads of $7.5 \mathrm{Kg}$. The experiments also show that the lowest specific fuel consumption occurs at the engine load of $7.5 \mathrm{Kg}$ with using the blend of 15-PRM out of all the engine loads considered in the study.
\end{abstract}

Keywords: Specific fuel consumption, Bio-fuels, Soybean-mustard oil blends, CVCRM engine test rig, engine loads

\section{Introduction}

Increase in demand in transport increases the fossil fuel demand. However, resources of these fuels are running out, prices of fossil fuels are expected to rise and the combustion of fossil fuels has detrimental effects on the climate. The expected scarcity of petroleum supplies and the negative environmental consequences of fossil fuels have spurred the search for renewable transportation bio-fuels. Vegetable oil is one of the renewable fuels. Vegetable oils have become more attractive recently because of its environmental benefits and the fact that it is made from renewable resources. Vegetable oils have the potential to substitute a fraction of petroleum distillates and petroleum-based petro chemicals in the near future. The basic constituent of vegetable oils is triglyceride.
The vegetable oils, as alternative engine fuels, are all extremely viscous with viscosities ranging from 9 to 17 times greater than that of petroleum-derived diesel fuel. Modern diesel engines have fuel-injection system that is sensitive to viscosity change. One way to avoid these problems is to reduce fuel viscosity of vegetable oil in order to improve its performance. The vegetable oils may be blended to reduce the viscosity with diesel in presence of some additives to improve its properties. Heating and blending of vegetable oils may reduce the viscosity and improve volatility of vegetable oils but its molecular structure remains unchanged, hence polyunsaturated character remains. Blending of vegetable oils with diesel, however, reduces the viscosity drastically and the fuel handling system of the engine can handle vegetable oil-diesel blends without any problems.

${ }^{*}$ Corresponding author. Tel.: + 911722753555

E-mail: drprajapati@pec.ac.in

(c) 2013 International Association for Sharing Knowledge and Sustainability

DOI: $10.5383 /$ ijtee.06.02.004 
An acceptable alternative fuel for engine has to fulfill the environmental and energy security needs without sacrificing operating performance. Vegetable oils can be successfully used in CI engine, through engine modifications and fuel modifications because vegetable oil in its raw form cannot be used in engines. It has to be converted to be a more enginefriendly fuel called bio-diesel. Bio-diesel has comparable energy density, cetane number, heat of vaporization, and air/fuel ratio with mineral diesel.

\section{Nomenclature}

Following terms are used in this paper:

$15 \mathrm{PRS}=$ Blending of $15 \%$ soya-bean oil with the petrol

$20 \mathrm{PRS}=$ Blending of $20 \%$ soya-bean oil with the petrol

$15 \mathrm{PRM}=$ Blending of $15 \%$ mustard oil with the petrol

$20 \mathrm{PRM}=$ Blending of $20 \%$ mustard oil with the petrol

$\mathrm{CO}=$ Carbon monoxide

$\mathrm{CO}_{2}=$ Carbon dioxide

HC's $=$ Hydrocarbons

CVCRM $=$ Computerized variable compression ratio multi-fuel

$\mathrm{p}=$ Pressure (in bar)

$\theta=$ Crank angle (in degree)

$\mathrm{V}=$ Volume (in \%)

MFB = Mass Fraction Burnt (in \%)

B.P $=$ Brake Power (in KW)

$\mathrm{EEOC}=$ Estimated end of combustion angle

\section{Literature Review}

Various efforts have been made to use various alternative fuels and literature review is summarized in this section. Papagiannakis and Hountalas [1] investigated the performance and emissions of dual fuel engine. The dual fuel engine can run on both liquid and the gaseous fuel. The gaseous fuel can be used as a replacement for liquid fuels. Some amount of diesel fuel can be replaced by the gaseous fuel (natural gas). They claimed that natural gas is the most attractive one because of is high auto ignition temperature. The emission of particulates is also very less as it contains very less dissolved impurities. The results show the effect of liquid fuel percentage replacement by natural gas on engine performance and emission.

Kim et al. [2] worked on the production of bio-diesel using the heterogeneous catalyst and prepared the biodiesel using transesterification process. A study for optimizing the reaction time, the stirring speed, use of co-solvent, oil to methanol ratio and the amount of catalysts was performed. The catalyst used was $\mathrm{Na} / \mathrm{NaOH} / \mathrm{y}-\mathrm{Al}_{2} \mathrm{O}_{3}$ as a base catalyst which shows the same activity as by the conventional homogenous catalyst. The basic strength of $\mathrm{Na} / \mathrm{NaOH} / \mathrm{y}-\mathrm{Al}_{2} \mathrm{O}_{3}$ catalyst was estimated. Yadav et al. [3] studied the effect of blending kerosene with petrol and diesel. Five fuel-adulterant mixtures in different proportions by volume were prepared and individually tested for density and kinematic viscosity. No appreciable density variation at different levels of adulteration was observed. Density was within the prescribed value even at higher adulteration. Considerable decrease in kinematic viscosity, a departure from prescribed viscosity, was noted at higher adulteration level. The percent opacity value decreased sharply even at small level of adulteration. The observations suggest density test is not a good indicator of diesel adulteration. Kinematic viscosity and opacity value are useful diesel adulteration test parameters. Meher et al. [4] worked on the production of biodiesel using technical aspects so as to get the best combination of the reactants used for the production. The biodiesel from the vegetable oil was produced by transesterification process by using monohydric alcohol in the presence of a suitable catalyst. The various parameters which affect the transesterification process are molar ratio of alcohol to oil, type of alcohol, type and amount of catalyst, reaction time and temperature and purity of reactant. They used different combinations of oil and catalysts in their study.

Barnard et al. [5] worked on the continuous flow preparation of bio-diesel using commercially available scientific microwave apparatus and presented that microwave heating for the production of biodiesel. Biodiesel proved to be the better way as it offers fast and better way. The vegetable oil to alcohol molar ratio used was $1: 6$. Reaction rate is about $7.2 \mathrm{~L} / \mathrm{min}$. using a 4L reaction vessel. Results showed that transesterification reaction was better than the conventional heating process. Refaat et al. [6] worked on production of biodiesel using waste vegetable oil and presented that biodiesel from the waste vegetable oil can be helpful in reducing the pollution from the water ways. Best yield of biodiesel was obtained at the molar ratio of $6: 1$ of methanol to oil. The yield percentage obtained was about $96 \%$ which is very close to the recommended standards of the biodiesel.

Akbar et al. [7] worked on jatropha curcas oil to use it as a feedstock for biodiesel and presented that jatropha oil can be used as a source of energy very attractively. Lipid fraction of jatropha was calculated and analyzed for physical and chemical properties such as acid value, percentage free fatty acids, iodine value, density, viscosity etc. The oil extracts exhibited physicochemical properties and could be useful as Biodiesel. Murugesan et al. [8] suggested that vegetable oils present a very promising scenario of functioning as alternative fuels to fossil diesel fuel. The properties of these oils can be compared favorably with the characteristics required for internal combustion engine fuels. Fuel related properties are reviewed and compared with those of conventional diesel fuel. Peak pressure development, heat release rate analysis and vibration analysis of the engine were discussed. Their results showed that the performance of biodiesel B20 is very close to that of the diesel. The percentage of emissions such as unburnt hydrocarbon, carbon monoxide and particulate matter were found to be decreased. Other parameters like heat release rate, peak pressure and vibrations were also examined.

Anbumani et al. [9] worked on two edible plant oils mustard and neem as diesel substitute. Oils were blended in the ratios of 10:90, 15:85, 20:80 and 25:75. Engine was run at different loads at constant speed on each blend and on the pure diesel and concluded that the performance of $20 \%$ of blend shows the closer performance to the diesel fuel and the performance of Mustard oil blend was better than the performance of Neem oil. Parameters like specific fuel consumption, thermal efficiency and peak pressure gave the satisfactory results. Kanan and Marappan [10] presented that diesel engine emission like nitrogen oxide $\left(\mathrm{NO}_{\mathrm{x}}\right)$ and soot particles are detrimental to human health and to the environment as a whole. Alternative fuels like biodiesel, ethanol, etc. are being used as effective replacements for diesel. In this study an oxygenated additive diethyl ether (DEE) was blended with bio diesel in the ratios of 
$5 \%, 10 \%, 15 \%$ and $20 \%$ and tested for their performance. The brake thermal efficiency of $20 \%$ blend was $29.4 \%$ which was $5 \%$ higher than biodiesel. Smoke was reduced by $14 \%$. Therefore, $20 \%$ blend gives the best performance and less emission as compared to others.

Jaichandar and Annamalai [11] presented that the biodiesel are very promising alternatives to diesel oil as a substitute in internal combustion engine. The biodiesel is defined as a transesterified renewable fuel derived from vegetable oils or animal fats with properties similar or better than biodiesel. The biodiesel can be used directly or indirectly by blending with the diesel in C.I. engine. Various parameters like thermal efficiencies, specific fuel consumption, engine power and viscosity were analyzed. Martin and Prithviraj [12] worked on the performance of compression ignition engine using blends of the cotton seed oil with diesel in C.I. engine. Performance, emission and combustion parameters were calculated at various loads using blended biodiesel and compared with the neat diesel. The $60 \%$ blend of biodiesel with the conventional diesel fuel gives the maximum efficiency and reduction in smoke or reduction in carbon monoxide and hydrocarbon emissions.

Ashhab et al. [13] studied of 8 different internal combustion fuels by conducting the various experiments. The 8 fuels were: octane 90 , octane 95 , blend of $10 \%$ methanol \& $90 \%$ octane 90 , blend of $10 \%$ methanol \& $90 \%$ octane 95 , blend of $20 \%$ methanol \& $80 \%$ octane 90 , blend of $20 \%$ methanol \& $80 \%$ octane 95 , blend of $30 \%$ methanol \& $70 \%$ octane 90 and blend of $30 \%$ methanol \& $70 \%$ octane 95 . A dynamometer setup was used to conduct the experiments and the emissions and torque at different speeds were measured. The efficiency, power and specific fuel consumption were calculated. The best fuels for internal combustion engines were recommended by them. Park et al. [14] investigated the emission reduction characteristics of bio-ethanol blended diesel fuel at early injection condition including spray, atomization and evaporation characteristics. The spray atomization and evaporation characteristics were investigated using spray visualization system and KIVA-3V code, respectively. In their work, the effect of ethanol blending on the spray behavior was more evident at the early injection condition. They suggested to reduce the droplets size for better atomization characteristics. They found that $\mathrm{HC}$ emission increases and the $\mathrm{CO}$ emission decreases with the blending of the ethanol. Rabu et al. [15] studied the properties of the biodiesel using American Society of Testing and Materials (ASTM) testing procedures (density, flash point, vapor pressure, viscosity, boiling point, melting point, and distillation T90) followed with evaluation to the Fatty Acid Methyl Ester (FAME) purity utilizing Flame Ionization Detector - Gas Chromatography Mass Spectroscopy (FID-GCMS). Results showed that the produced biodiesel fall within the standard range and with a best yield of $93 \%$ at $12: 1$ alcohol to oil ratio, at temperature of $60^{\circ} \mathrm{C}$, and reactor agitation speed of $400 \mathrm{rpm}$ (400 rpm or $500 \mathrm{rpm}$ - see table 2). Biodiesel fuel blends B05, $\mathrm{B} 10, \mathrm{~B} 15$ and B20 were prepared and tested in a small 8 horse power Robin Diesel Engine. The torque and the break engine horsepower were obtained using engine dynamometer. Real time monitoring of engine emissions was performed using gas analyzer. The details of apparatus and preparation of bio-fuels are discussed in the next section.

\section{Description of apparatus and preparation of bio-fuels}

The computerized variable compression ratio multi-fuel engine test rig is an automatic engine which makes our work easier by calculating the various parameters. Both petrol and diesel fuels may be used on this engine. The compression ratio can be varied from 5:1 to 20:1. The load can also be varied from 0-10 KG. By varying the load or the compression ratio the efficiencies and the specific fuel consumption may be calculated. The minimum fuel required for proper engine functioning is 5 litre. The engine contains two sensors one for petrol and other for diesel. Their main function is to decide the range of fuel level. Specification of computerized variable compression ratio multi-fuel engine test is shown in Table 1.

Table 1 Specifications of computerized variable compression ratio multi-fuel engine test rig

\begin{tabular}{|l|l|}
\hline Make & LEGION BROTHERS \\
\hline BHP & $3-5 \mathrm{HP}$ \\
\hline Speed & $\begin{array}{l}1450-1600 \quad \text { r.p.m. variable governed } \\
\text { speed }\end{array}$ \\
\hline No. of cylinder & 1 \\
\hline Compression ratio & $5: 1$ to 20:1 \\
\hline Bore & $80 \mathrm{~mm}$ \\
\hline Stroke & $110 \mathrm{~mm}$ \\
\hline Type of ignition & $\begin{array}{l}\text { Spark ignition (time adjustment: 0-70 } \\
\text { degree } \\
\text { ATDC: 0-70 degree BTDC or } \\
\text { Compression ignition }\end{array}$ \\
\hline Method of loading & Eddy current dynamometer \\
\hline Method of cooling & Water \\
\hline
\end{tabular}

\subsection{Preparation of bio-fuel from vegetable oil}

Production of bio-diesel was carried out using a bio-fuel reactor. Bio-fuel reactor contains magnetic stirrer, condenser, flask, pump and the tub. The raw material used was vegetable oil (mustard oil or refined Soyabean oil). One litre of vegetable oil along with methanol (in appropriate quantity, depending on the oil used) was mixed in the round bottom flask. Five grams of catalyst (potassium hydroxide) was added in the mixture, as shown in Fig. 1. Similarly, mixture of mustard oil is shown in Figure 2.

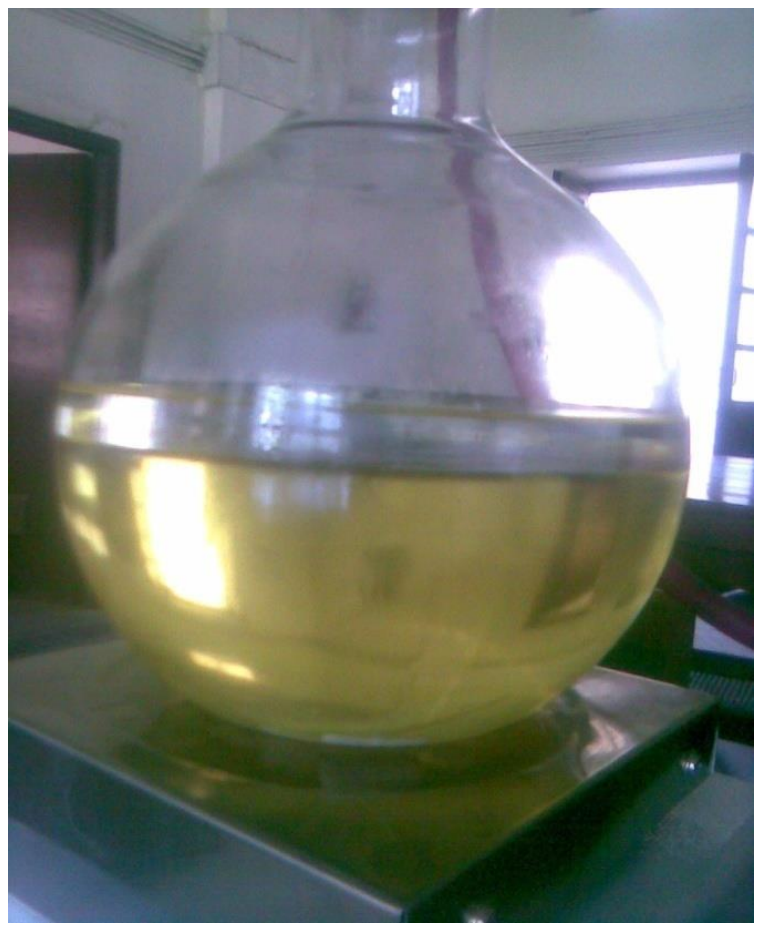

Fig. 1 Soyabean oil mixture before starting the operation 


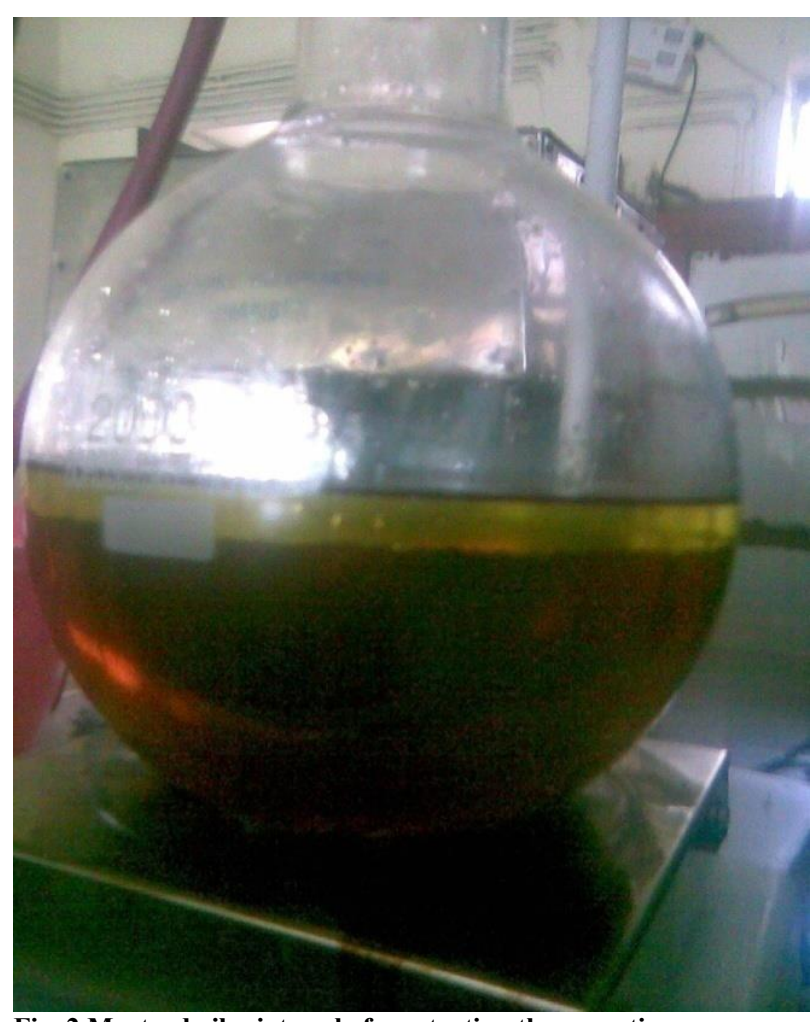

Fig. 2 Mustard oil mixture before starting the operation

The whole mixture (oil + catalyst + methanol) is heated up to the temperature of about 60 degree Celsius and is stirred at a constant r.p.m. For Soyabean oil, the whole process is allowed to run for 1 hour 30 minutes and for mustard oil the whole process is allowed to run for 1 hour 15 minutes approximately. When the process is over, the mixture is allowed to settle for at least 4 hours. Two layers are observed after settling of the mixture, the upper and the bottom layer as shown in Fig 3. The ester is visible in the upper layer and the glycerol in the bottom layer. The layers are separated using separating funnel and the glycerol is removed from the mixture. After removing glycerol from the ester, the warm water is added to the remaining part of the ester. The mixture is shaken for 4 to 5 times and mixture is then kept undisturbed for next 1 hour. Again two layers are observed, the upper layer is of bio-fuel and the lower one is of impure solution of potassium hydroxide with the water as shown in Fig. 4.

Meher et al. (2006) defined transesterification as the process of separating the fatty acids from their glycerol backbone to form fatty acid esters (FAE) and free glycerol. Fatty acid esters commonly known as biodiesel can be produced in batches or continuously by transesterifying triglycerides such as animal fat or vegetable oil with lower molecular weight alcohols in the presence of a base or an acid catalyst. This reaction is shown in Equation (1).

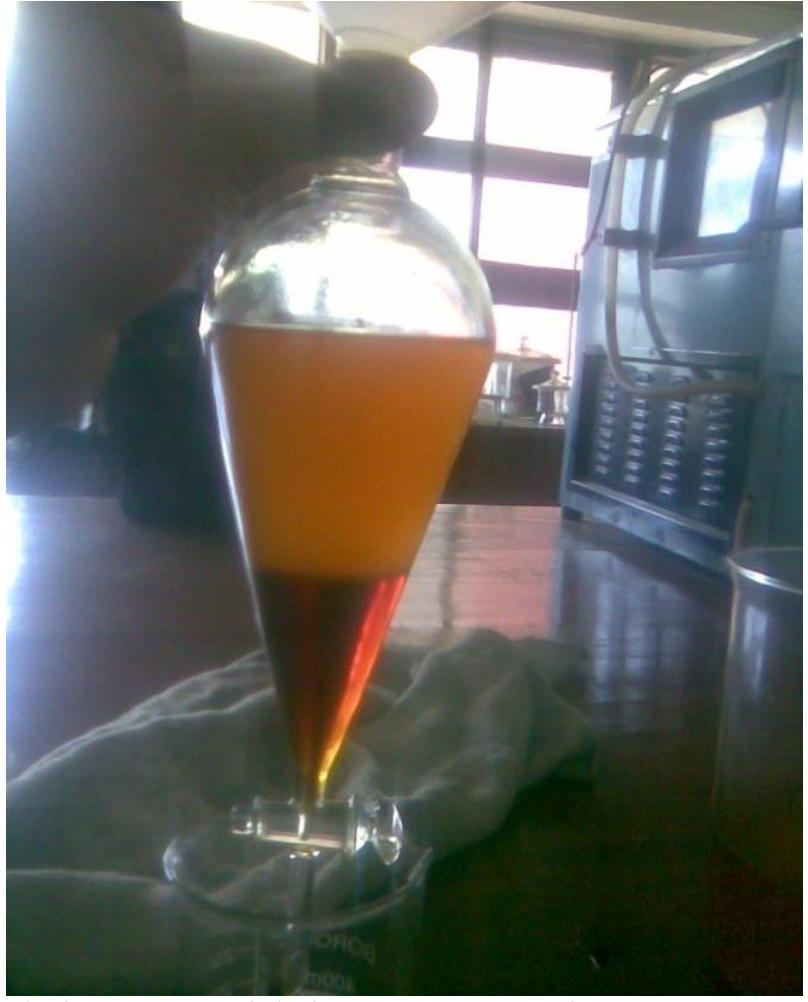

Fig. 3 Upper layer of bio-fuel and lower layer of glycerol

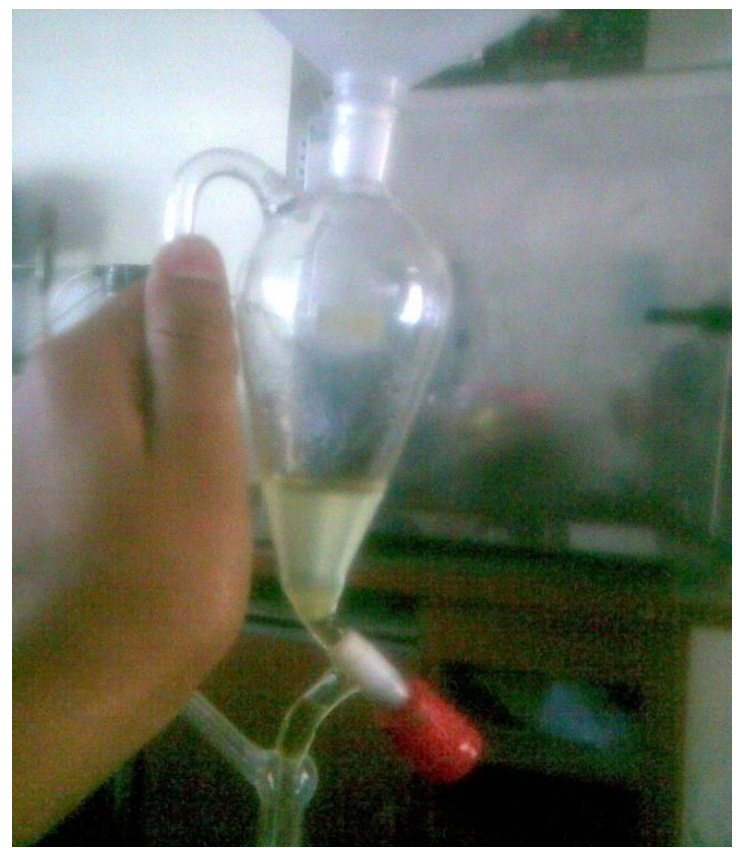

Fig. 4 Upper layer of esters and lower of potassiuhydroxide solution

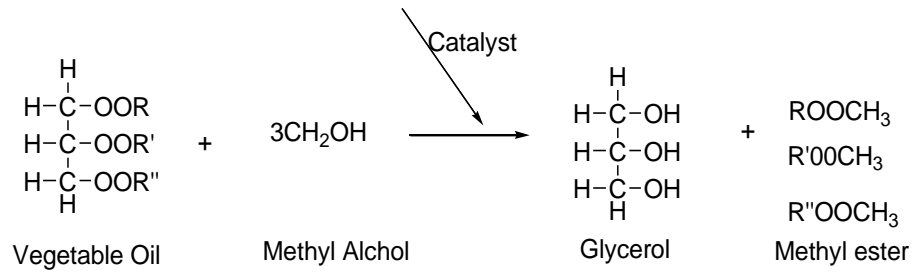




\subsection{YIELD OF BIO-FUEL}

\subsubsection{Soyabean mixed fuel:}

Soyabean oil $=1$ litre

Methanol used $=168 \mathrm{ml}$

Catalyst used: Potassium hydroxide $(\mathrm{KOH})=5 \mathrm{gm}$

Time taken for experiment $=1.30$ hours

Temperature $=61^{\circ} \mathrm{C}$

Maximum yield of bio-fuel $=900 \mathrm{ml}$

\subsubsection{Mustard oil mixed fuel:}

Mustard oil $=1$ litre

Methanol used $=220 \mathrm{ml}$

Catalyst used: Potassium hydroxide $(\mathrm{KOH})=5 \mathrm{gm}$

Time taken for experiment $=1.15$ hours

Temperature $=59^{\circ} \mathrm{C}$

Maximum yield of bio-fuel $=983 \mathrm{ml}$

For soyabean oil $168 \mathrm{ml}$ is the maximum amount of methanol, which may be added in the vegetable oil for the transesterification reaction and for the mustard oil, the maximum amount of methanol added is $220 \mathrm{ml}$. If more methanol is added then it remains un-reacted in the mixture and floats on the top surface which leads to the wastage of methanol and money.

\subsection{ANALYSIS OF SPECIFIC FUEL CONSUMPTION}

Specific fuel consumption (SFC) reflects the engine performance. It can be defined as the ratio of weight of the fuel to the brake horse power (BHP) in kilogram per kilowatt hour. $S F C=\left(W_{f} / B H P\right)$

Where,

$$
\begin{aligned}
& \mathrm{W}_{\mathrm{f}}=\text { Weight of the fuel } \\
& \begin{aligned}
\mathrm{BHP} & =\text { Brake horse power } \\
& =\text { (Indicated horse power)/ Mechanical Efficiency }
\end{aligned}
\end{aligned}
$$

Variations in the specific fuel consumption (SFC) of fuels with respect to change in engine load are shown in this section. Table 2 shows the specific fuel consumption (SFC) of engine with using the petrol (only) with respect to change in the loads.

Table 2 Specific fuel consumption at various loads using petrol (only)

\begin{tabular}{|c|c|}
\hline LOAD $(\mathrm{Kg})$ & SFC (in $\mathrm{Kg} / \mathrm{KWh}$ ) \\
\hline 2.5 & 1.105 \\
\hline 5.0 & 0.539 \\
\hline 7.5 & 0.374 \\
\hline
\end{tabular}

The variation in the specific fuel consumption (in $\mathrm{Kg} / \mathrm{KWh}$ ) with blending of $15 \%$ soya-bean oil with the petrol (15-PRS) with respect to change in the engine loads is shown in Table 4.

Table 3 Specific fuel consumption at various loads using the blend of 15-PRS

\begin{tabular}{|c|c|}
\hline LOAD $(\mathrm{Kg})$ & SFC (in $\mathrm{Kg} / \mathrm{KWh})$ \\
\hline 2.5 & 1.096 \\
\hline 5.0 & 0.526 \\
\hline 7.5 & 0.400 \\
\hline
\end{tabular}

Table 4 shows variation in the specific fuel consumption (in $\mathrm{Kg} / \mathrm{KWh}$ ) with blending of $20 \%$ soya-bean oil with the petrol (20-PRS) with respect to change in the engine loads.
Table 4 Specific fuel consumption at various loads using the blend of 20-PRS

\begin{tabular}{|c|c|}
\hline LOAD $(\mathrm{Kg})$ & SFC (in $\mathrm{Kg} / \mathrm{KWh})$ \\
\hline 2.5 & 1.513 \\
\hline 5.0 & 0.541 \\
\hline 7.5 & 0.409 \\
\hline
\end{tabular}

Table 5 shows variation in the specific fuel consumption (in $\mathrm{Kg} / \mathrm{KWh}$ ) with blending of $15 \%$ mustard oil with the petrol (15-PRM) with respect to change in the engine loads.

Table 5 Specific fuel consumption at various loads using the blend of 15-PRM

\begin{tabular}{|c|c|}
\hline LOAD (Kg) & $\begin{array}{c}\text { SFC (in } \\
\mathrm{Kg} / \mathrm{KWh})\end{array}$ \\
\hline 2.5 & 1.105 \\
\hline 5.0 & 0.535 \\
\hline 7.5 & 0.390 \\
\hline
\end{tabular}

The variation in the specific fuel consumption (in $\mathrm{Kg} / \mathrm{KWh}$ ) with blending of $20 \%$ mustard oil with the petrol (20-PRM) with respect to change in the engine loads is shown in Table 6.

Table 6 Specific fuel consumption at various loads using the blend of 20-PRM

\begin{tabular}{|c|c|}
\hline LOAD (in $\mathrm{Kg})$ & SFC (in Kg/KWh) \\
\hline 2.5 & 1.142 \\
\hline 5.0 & 0.541 \\
\hline 7.5 & 0.414 \\
\hline
\end{tabular}

\section{Results and Discussion}

The variations in specific fuel consumption (in $\mathrm{Kg} / \mathrm{KWh}$ ) of various blends of bio-fuels are shown in the above section but their comparison and discussion is presented in this section.

Table 7 shows the comparison of the specific fuel consumption (in $\mathrm{Kg} / \mathrm{KWh}$ ) of different bio-fuels used in the engine.

\begin{tabular}{|c|c|c|c|c|c|}
\hline $\begin{array}{l}\text { Load } \\
\text { (in } \\
\mathrm{kg} \text { ) }\end{array}$ & \begin{tabular}{l}
\multicolumn{1}{c}{ SFC } \\
(in Kg/ \\
KWh) \\
with \\
Petrol \\
(only) \\
\end{tabular} & $\begin{array}{c}\text { SFC } \\
\text { (in } \\
\mathrm{Kg} / \mathrm{KWh} \text { ) } \\
\text { with 15- } \\
\text { PRS }\end{array}$ & $\begin{array}{l}\text { SFC } \\
\text { (in } \\
\mathrm{Kg} / \mathrm{KWh} \\
\text { ) } \\
\text { with20- } \\
\text { PRS }\end{array}$ & $\begin{array}{c}\text { SFC } \\
\text { (in } \\
\mathrm{Kg} / \mathrm{KWh} \\
\text { ) with } \\
\text { 15-PRM }\end{array}$ & $\begin{array}{c}\text { SFC } \\
\text { (in } \\
\mathrm{Kg} / \mathrm{KWh} \text { ) } \\
\text { with 20- } \\
\text { PRM }\end{array}$ \\
\hline 2.5 & 1.142 & 1.513 & 1.105 & 1.105 & 1.096 \\
\hline 5.0 & 0.541 & 0.541 & 0.535 & 0.539 & 0.526 \\
\hline 7.5 & 0.414 & 0.409 & 0.390 & 0.374 & 0.400 \\
\hline
\end{tabular}

Table 7 Comparison of specific fuel consumption (in $\mathrm{Kg} / \mathrm{KWh}$ ) of different fuels

Following facts are observed from the Table 7:

(i) Out of the two soya-bean oil blends, 20-PRS shows the lowest specific fuel consumption (in $\mathrm{Kg} / \mathrm{KWh}$ ) at all the engine loads i.e. $2.5 \mathrm{Kg}, 5 \mathrm{Kg}$ and $7.5 \mathrm{Kg}$.

(ii) Out of the two mustard oil blends, 20-PRM shows the lowest specific fuel consumption (in $\mathrm{Kg} / \mathrm{KWh}$ ) at the engine loads of $2.5 \mathrm{Kg}$ and $5.0 \mathrm{Kg}$, where as 15 PRM shows the lowest specific fuel consumption (SCF) at the engine loads of $7.5 \mathrm{Kg}$.

(iii) At the load of $2.5 \mathrm{Kg}$, the blend of 20-PRM shows the lowest specific fuel consumption (in $\mathrm{Kg} / \mathrm{KWh}$ ) while 15-PRS shows highest specific fuel consumption compared to all other blends. 
(iv) At the load of $5.0 \mathrm{Kg}$, the blend of 20-PRM shows the lowest specific fuel consumption while 15-PRS and Petrol (only) show highest specific fuel consumption compared to all other blends.

(v) At the load of $7.5 \mathrm{Kg}$, the blend of 15-PRM shows the lowest specific fuel consumption (in $\mathrm{Kg} / \mathrm{KWh}$ ) while Petrol (only) shows highest specific fuel consumption compared to all other blends.

(vi) The specific fuel consumption (SFC) decreases on increasing the engine load for all the fuels used in the engine in experimentation.

(vii) The highest specific fuel consumption (1.513) occurs at the engine load of $2.5 \mathrm{Kg}$ with using the blend of 15 -PRS out of all the engine loads considered in the experiment.

(viii) The lowest specific fuel consumption (0.374) occurs at the engine load of $7.5 \mathrm{Kg}$ with using the blend of 15 -PRM out of all the engine loads considered in the experiment.

\section{Conclusions}

Due to the rapid decline in crude oil reserves, the use of vegetable oils as diesel fuels is again promoted in many countries. Depending on climate and soil conditions, different nations are looking into different vegetable oils for diesel fuels. For example, Soyabean oil in the USA, rapeseed and sunflower oils in Europe, palm oil in Southeast Asia (mainly Malaysia and Indonesia), and coconut oil in Philippines are being considered as substitutes for mineral fuel. Vegetable oils are liquid fuels from renewable sources; they do not over-burden the environment with emissions. Vegetable oils have potential for making marginal land productive by their property of nitrogen fixation in the soil. Currently, the cost of bio-fuel is high compared to conventional diesel oil because most of the bio-fuel is produced from pure vegetable oil. Extensive use of edible oils may cause other significant problems such as starvation in developing countries.

A comparative study and comparison of the specific fuel consumptions (in $\mathrm{Kg} / \mathrm{KWh}$ ) have been presented in the paper. The comparisons have been made among the five fuels which are prepared from the blending of soya-bean and mustard oils with petrol. It is found that the out of the two soya-bean oil blends, 20-PRS shows the lowest specific fuel consumption (in $\mathrm{Kg} / \mathrm{KWh}$ ) at all the engine loads considered in the study, while out of the two mustard oil blends, 20-PRM shows the lowest specific fuel consumption at the engine loads of $2.5 \mathrm{Kg}$ and 5.0 $\mathrm{Kg}$, where as 15-PRM shows the lowest specific fuel consumption (SCF) at the engine loads of $7.5 \mathrm{Kg}$. Similarly, the highest specific fuel consumption occurs at the engine load of $2.5 \mathrm{Kg}$ with using the blend of 15 -PRS out of all the engine loads considered in the experiment.

\section{ACKNOWLEDGMENT}

We are very grateful to the reviewer(s) for their valuable suggestions to improve this paper, suitable for the publication in the Int. J. of Thermal \& Environmental Engineering.

\section{References}

[1] Papagiannakis, RG, Hountalas, HT. Experimental investigation concerning the effects of natural gas percentage on performance and emissions of a DI dual fuel diesel engine", Applied thermal energy, Vol. 23, pp. 353365.

[2] Kim, HJ, Kang B, Kim, M, Park, YM, Kim, D, Lee J, Lee K. (2004), Transesterification of vegetable oil to biodiesel using heterogeneous base catalyst", Catalysis today 2004, 93-95: 315-320.

[3] Yadav R, Murthy VK, Mishra D, Baral D. Estimation of petrol and diesel adulteration with kerosene and assessment of usefulness of selected automobile fuel quality test parameters. International Journal of Environmental Science \& Technology 2005: 1: 4: 253-255.

[4] Meher LC, Sagar DV, Naik NK. Technical aspects of Biodiesel production by transesterification. Renewable and sustainable Energy Reviews 2006:10:3:248-268.

[5] Barnard TM, Leadbeater NE, Boucher MB, Stencel LM, Wilhite BA. Continuous flow preparation of Biodiesel using Microwave heating. Energy and Fuels 2007: 21: 1777-1781.

[6] Refaat AA, Attia NK, Sibak HA, Sheltawy ST, Diwani GI. Production optimization and quality assessment of biodiesel from waste vegetable oil. International journal of environmental sciences and technology 2008: 5:1:75-82.

[7] Akbar E, Yaakob Z, Kamarudin SK, Ismail M, Salimon J. Characteristics and composition of jatropha curcas oil seed from Malaysia and its potential as Biodiesel Feedstock. European journal of scientific research 2009:29:3:396-403.

[8] Murugesan A, Umarani C, Subramanian R, Nedunchezhian N. Biodiesel as an alternative fuel for diesel engine. Renewable and sustainable energy reviews 2009:13:653662.

[9] Anbumani K, Singh AP. Performance of Mustard and Neem oil Blends with Diesel fuel in C.I engine. ARPN Journal of engineering and applied sciences 2010: 5:4:14-20.

[10] Kannan TK, Marappan R. Study of performance and emission characteristics of a diesel engine using Thevetia Peruviana biodiesel with diethyl ether blends. European journal of scientific research 2010:43: 4:563-570.

[11] Jaichandar S, Annamalai K. Status of biodiesel as an alternative fuel for diesel engine. Journal of sustainable energy and environment 2011: 2:71-75.

[12] Martin M, Prithviraj D. Performance of preheated cotton seed oil and diesel fuel blends in a compression ignition engine. Jordan journal of mechanical and industrial engineering 2011:5: 3:235-240.

[13] Ashhab MS, Abu-Zaid M, Baqaeen O, Khdair M, Adel E. Experimental Study of Emissions and Performance of Internal Combustion Engine Fuels. Int. J. of Thermal \& Environmental Engineering 2011: 3:95-100.

[14] Park SHC, Junepyo K, Hyung J, and Lee, CS. Effect of early injection strategy on spray atomization and emission reduction characteristics in bioethanol blended diesel fueled engine. Energy 2012:39:1-13.

[15] Rabu RA, Janajreh I, Ghenai G. Transesterification of Biodiesel: Process Optimization and Combustion Performance. Int. J. of Thermal \& Environmental Engineering 2012: 4: 2:129-136. 